\title{
Studying the Value of the University Armed Service Units: Research Rationale and Methods
}

In this chapter, we introduce the research underpinning this book by noting the origins and rationale for that research. We explain the research methodology used, and discuss areas of investigation deliberately excluded from the study.

\subsection{Rationale and background to the research}

The origins of the research lie in conversations between members of the research team and individuals associated with the Northumbrian Universities Military Education Committee (NUMEC), about the possibility of undertaking a study of the value added to students and value returned to the armed forces of the USUs. ${ }^{46}$ The research team were receptive to the idea, given their existing interests in the sociology and politics of the armed forces, and their roles in higher education as members of academic staff at Newcastle University. We noted at the time the absence of information in the public domain about the university armed service units, both generally beyond those who had direct experience of USUs, and more specifically within the academic military sociological literature.

${ }^{46}$ The initial proposal was for a study solely of the UAS.

How to cite this book chapter:

Woodward, R, Jenkings, K N and Williams, A J. 2015. The Value of the University Armed Service Units. Pp. 31-43. London: Ubiquity Press. DOI: http://dx.doi. org/10.5334/baq.b. License: CC-BY 4.0. 


\subsubsection{The pilot study}

In the academic year 2009-10, Dr Alison Williams applied for and was awarded funding from Newcastle University's Catherine Cookson Foundation to undertake a pilot project exploring graduate skills and the USU experience. ${ }^{47}$ This study focused on the three service units in the North East of England, the Northumbrian Universities Royal Naval Unit, Northumbrian Universities Officer Training Corps and Northumbrian Universities Air Squadron, which draw students from the five local universities of Newcastle, Durham, Northumbria, Sunderland and Teesside. This research showed the extent to which students identified the skills development they received through their USU experience as valuable, and suggested the viability of a bigger, national study.

\subsubsection{The Value of the University Armed Service Units study}

On the basis of the pilot project, funding for further study was sought from the Economic and Social Research Council (ESRC) to support a more comprehensive and ambitious national project. The ESRC is one of seven UK research councils, and provides research funding through grants at full economic cost to (primarily) higher education institutions in the UK for social science research. The ESRC is funded through the DBIS but is entirely independent of government in terms of its distribution of funds. Applications under the response mode scheme are not limited by topic, theme or approach. They are peer-reviewed, and the process is highly competitive. The application was submitted in December 2011 with Dr Alison Williams as Principal Investigator and Dr K. Neil Jenkings and Professor Rachel Woodward as CoInvestigators, was awarded in August 2012, and the research commenced in December 2012. Given the length of time between submission of the application and the start of the research, it is perhaps unsurprising that policy changes emerged between the start of the project planning and the start date of the actual research, and this was evident with the emergence of the Future Force 2020 agenda and its inclusion of strategies to reduce the overall size of the three armed forces and increase the proportion of reservists, particularly in the British Army.

The research had two core objectives. The first objective was to assess the value of the military experience provided by the USUs. We examined this with reference to student participants, graduates in civilian employment who had had a USU experience as a student, the armed forces, the universities and

${ }^{47}$ Williams, A., Egdell, V. and Woodward, R. (2010). Graduate Skills and the University Armed Service Units Experience. Retrieved from http://research.ncl.ac.uk/military-research/assets/ docs/'Graduate-Skills-and-the-University-Armed-Service-Unit-Experience.pdf 
employers and the wider labour market. The methodologies used to assess this question of value are outlined in section 2.2 below, and included a quantitative survey of participating students, and semi-structured interviews with graduates, unit $\mathrm{COs}$ and university and employer representatives. The intention was to establish whether, and if so how, value was understood, working with a preliminary understanding of value in non-financial terms and as manifest through individual, social and institutional benefits. Exploring respondents' understandings of what value might constitute in context of the USUs was an important element to this. This book focuses on research findings which speak to the first research objective.

The second research objective was to explore how this notion of value around the USU experience might then be used to extend and inform more conceptual debates about militarism, militarisation and civil-military relations. Informed by the analysis of empirical data around the value of the USUs, we were interested in questions such as how the relational categories of 'military' and 'civilian' are brought into being and performed within the USU context, and how current conceptualisations within the social sciences of militarism and militarisation might be confirmed, extended or challenged by consideration of the USU experience as a process which facilitates the extension of military presence, ideas and understandings into civilian life. We were particularly interested in the spatialities of militarism, looking explicitly at education and the workplace as locations where processes of militarisation might or might not be identified on the basis of USU influence. ${ }^{48}$ These more conceptual issues are not discussed here, but are the focus for academic journal articles.

\subsubsection{Research ethics}

The research was conducted in accordance with ESRC guidelines for the ethical conduct of social science research. Ethical reviews were conducted as part of the ESRC research grant application process, and subsequent to award by the Newcastle University Faculty of Humanities and Social Sciences Research Ethics Committee. This ensured that the research was compliant with research ethics policies covering research validity, risk assessment, researcher safety, participant recruitment strategy, consent procedures, vulnerable groups, confidentiality and review of ethical issues within the project as it proceeded. Because this research was not funded by the MoD or armed forces, it was not subject to review by the MoD Research Ethics Committee.

${ }^{48}$ For further discussion of the geographies of militarism and militarisation, see: Woodward, R. (2004). Military Geographies. Oxford: Blackwell; Rech, M. F., Bos, D., Jenkings, K. N., Williams, A. J. and Woodward, R. (2015). Geography, military geography and critical military studies. Critical Military Studies, 1 (1), 47-60. 


\subsubsection{Steering group}

The research was conducted according to the guidelines and expectations of ESRC. Included in these is an expectation that where research results are of potential utility or interest to research users or beneficiaries, those research users where possible should be involved in the preparation and execution of that research. This expectation recognises the independence of ESRC-funded research, whilst also recognising the benefits that follow to that research from research user engagement. Accordingly, the initial research design benefitted from consultations with the following: representatives from the Reserve Forces and Cadets division working under the Deputy Chief of Defence Staff Personnel \& Training, who have responsibility for the USUs; from representatives at the Royal Military Academy Sandhurst, Britannia Royal Naval College and RAF College Cranwell with responsibilities for the units and for officer training; from the Council of Military Education Committees and from our local Northumbrian Universities Military Education Committee. These organisations subsequently joined a steering group which met three times over the period of research data collection. The steering group also included a representative of the Newcastle University Careers Service. We would like to record our thanks for the input of our steering group members; the research benefitted in many significant ways from their advice, and we are grateful for their time and input. However, the results and conclusions are our own, and do not necessarily reflect those of our steering group members or their respective organisations.

\subsubsection{Conceptualising value}

This project was about value, and investigating the concept of value was one of our research objectives (see section 2.1.2 above). As a concept underpinning the research, we understood value in terms of utility, benefit and advantage. The research did not set out to quantify value in economic or financial terms, and was not an exercise in cost-benefit analysis. Rather, the research explored what value might mean and might be defined as, with regards to the multiple ways in which that value might be manifest, observed or experienced by the groups on which we focused. We were concerned with value rather than values, and although a number of ethical and moral issues emerged in the data which indicated that the idea of value might incorporate ideas about values, our focus was emphatically on the former rather than the latter.

\subsubsection{The research team}

The research team comprised Dr Alison Williams (Principal Investigator),

Dr K. Neil Jenkings (Co-Investigator and full-time project researcher) and 
Professor Rachel Woodward (Co-Investigator), all based at the School of Geography, Politics \& Sociology, Newcastle University, UK. The research team brought to the research their combined and considerable teaching experience in higher education contexts, experience in university administration and experience as social science researchers. Alison Williams' research has focused on political geography and geopolitics, aerial geographies (particularly in military contexts) and graduate and transferable skills education. ${ }^{49} \mathrm{~K}$. Neil Jenkings' research has focused on the sociology of workplace practices, social interactions and the relationships between armed forces and society in social and cultural contexts. ${ }^{50}$ Rachel Woodward's research has focused on the sociology of the military, military geographies and military identities and relations (including gender identities and relations) in armed forces contexts. ${ }^{51}$ One member of the research team had prior experience of employment with the British armed forces, and one had prior experience as a member of a USU for a short period of time whilst at university.

\subsection{Research methodology}

The research used a mixed methods approach, deploying both quantitative and qualitative methods of data collection and analysis. The advantage of a mixed methods approach is that it provides different types of data, generated using different methods of collection and subject to analysis using different techniques. Quantitative methods analyse numerical data from either primary sources (collected to answer a specified research question) or secondary sources (data collected for other purposes which can be used for specific purposes possibly unintended at time of generation). Quantitative methods are used to test hypotheses and deploy deductive reasoning from the general to the specific. Qualitative methods analyse textual, oral and visual data, and again may be used on either primary or secondary data sources. Qualitative methods are used to explore meaning and individual understanding in social contexts, and deploy inductive reasoning from the specific to the general. There is increasing consensus within the academic social science research community about the utility of using both quantitative and qualitative methods in combination, particularly when analysing complex social phenomena. Because of the complexity and range of issues pertaining to the key question about the value of the USUs, a mixed methods approach was identified as most appropriate for this research.

${ }^{49}$ Alison Williams' profile is available at: http://www.ncl.ac.uk/gps/staff/profile/alison.williams1

${ }^{50} \mathrm{~K}$. Neil Jenkings' profile is available at: http://www.ncl.ac.uk/gps/staff/profile/neil.jenkings

${ }^{51}$ Rachel Woodward's profile is available at: http://www.ncl.ac.uk/gps/staff/profile/rachel. woodward 


\subsubsection{The survey of current student university armed service units participants}

A quantitative survey was conducted of current student participants in USUs, in order to generate data on the demographics of the group, their perceptions of their USU experience, their motivations for joining a unit, their understanding of the benefits and disbenefits of their USU experience and their intentions with regards to a future career with the armed forces. A copy of the questionnaire is included in Appendix 1. Questions were either closed (requiring either a yes/no answer or selection from a list of potential responses), used a Likert scale (requiring a response on a sliding scale) or were open (requiring respondent completion using free text), and generated both numeric and textual data. In the interests of maximising participation, individuals completing the survey were able, if they chose, to skip a question and move to the next. Although an instrument which demands that participants complete all questions sequentially has the advantage of ensuring responses to all the questions, it has the disadvantage of lowering response rates if respondents have difficulties with a particular question. An additional compounding factor is overexposure to surveys, creating lower response rates; a particular methodological issue when researching students given the significant numbers of student opinion surveys conducted at module, degree programme and institutional level, and more generally for commercial purposes.

The survey instrument was a web-based online questionnaire, and was developed using SurveyMonkey software. Respondents to the survey were required to use a web link to gain access. Given the ubiquity of internet access, particularly amongst the target group, the use of an online survey instrument was felt to be the most appropriate mechanism to use, and no paper copies of the survey were distributed. This limited completion of the questionnaire to those who had access to the web link, which was distributed by COs, with agreement from the central leads for each service unit. Because of variations across the three services, and between units within each service, it is possible that approaches towards distributing the link varied across the sample. We also recognise that although the information given to the students made clear that the survey was being conducted by independent researchers, it is possible that because this information was distributed by COs it may still have been perceived by students as an official defence survey. However, the use of central gatekeepers (unit COs) was necessary because of data protection legislation and protocols preventing the sharing of student email addresses between third parties. COs were able to provide briefings to their students about the survey, and thus some variation in the description of the form and function of the survey was inevitable. The voluntary nature of participation was made clear to students, and a small prize offered as an inducement to participate.

The survey was distributed to all serving USU participants (in the OTC, UAS and URNU) and in all units, between January and April 2013. The timing of the 
survey was deliberate in order to capture the experiences of newer members who may only have joined a unit in the previous three or four months, and of established members who may have had a much longer period of participation (up three and a half years for those on four-year degree programmes) and who were in the process of completing their education and determining future career objectives.

A total of 1,798 students completed the survey. Of this total, 842 respondents (47\%) were from OTC units, 656 (36\%) were from UAS units and $285(16 \%)$ were from the URNU. As a proportion of all students across all USUs for the academic year 2012-13, and using Defence Statistics estimates for that total USU population (see 1.1.1. above), we calculate the proportion of responses per each of the three services to be $19 \%$ for OTC (4,400 members, with a sample of 842$), 59 \%$ for UAS (1,110 members, with a sample of 656$)$ and $34 \%$ for URNU (850 members, with a sample of 285). Expected response rates for online surveys targeted at students vary quite markedly according to the demographic composition of a student body and institutional characteristics, and the response rates achieved in this case lie within an expected range. However, the figures for total USU population available through Defence Statistics will include both active participants, and those who are enlisted as members but who, for whatever reason, are not active in their units. The calculated response rate is likely to be an underestimation in terms of responses from active participants, and accordingly we would estimate our total and unit-specific sample to be higher than that indicated above.

The data collected through the questionnaire survey was 'cleaned' and entered into both SPSS version 21 (an IBM software package for the statistical analysis of social science data) and Excel, for analysis. Given the intended uses of the analysis and the research questions and hypotheses framing this, a decision was taken to focus analysis of numeric data on simple statistics rather than more complex forms of parametric and non-parametric statistical testing. Non-numeric data was manually coded where appropriate, for responses to questions requiring or providing the option of a free-text response and for responses requiring identification of university, degree programme and unit.

The statistical data used in this book is all taken from the survey of student USU participants, except where indicated. For the purposes of clarity, all percentages have been rounded up or down to the nearest whole number. Percentages have been calculated on the basis of total valid responses to a question, rather than on total response rates overall, to account for the fact that some questions did not generate a full response (for example, were missed by 10 to 20 participants).

\subsubsection{Interviews with graduates of university armed service units}

Qualitative interviews were conducted with individuals who had participated in a USU as a student but had not gone on to pursue a career in the armed 
forces. The purpose of these interviews was to explore the value of the USU experience from the perspective of former participants who had now embarked on careers in the civilian workplace (including those who had retired). We wanted to establish whether their USU experience had had value for them in their working lives and beyond, and the wider understanding of former members of the value (or otherwise) of their USU experiences in their lives to date.

Although we recruited participants on the basis of USU experience, in fact a number of respondents revealed during the course of their interview that they also had experience with the Reserve forces. We did not exclude these individuals from our analysis, because of the valuable insights that this sub-group were able to bring to the issue of the relationship between USU and Reserves participation (see section 1.4.5. above). At the time of the interviews, there was substantial and ongoing press coverage of the Future Force 2020 programme.

Interviewees were recruited through social media networks, including unit alumni pages and through snowballing from initial contacts. The original intention had been to interview up to 40 former USU participants. In fact, we interviewed 54 individuals, a reflection of the wide range of insights these individuals were able to share and the richness of the data that the interviews generated. We interviewed 24 former OTC members, 13 former UAS members and 17 former URNU members. Some individuals had experience with more than one service (for example, changing service unit when graduating from one university and entering another for postgraduate study), and we have allocated those individuals to the service unit they first joined. It would not have been possible to get a meaningful representative sample across categories such as unit location, degree subject or class or other sociodemographic factors. The sampling strategy therefore aimed to be broadly representative across age span and gender, and with the aim of generating interviewees across a range of localities and occupations (so not, for example, just recruiting individuals working in London for large corporations).

Further details about the sample are given in Chapter 4. In brief, all respondents at the point of interview were either in paid employment, were taking leave or other time out for childcare or were retired. Respondents ranged in age from their early 20 s to their mid-70s, with the majority in their mid-20s to late 30 s. Respondents were self-selecting. It has been suggested that there might be participation bias in the sample, with only those positively inclined towards the USUs ready to come forward for interview. However, a feature of data collection using semi-structured interviews is the fact that the technique is designed to tease out the range of ideas, knowledge, experience and understanding from interviewees, something that rests to no small degree on the skill and expertise of the interviewer. Furthermore, it would of course be extremely poor research practice to select a sample on the basis of a pre-determined assessment of their positive or negative views towards a specific social phenomenon. Nor did we attempt to recruit a sub-group within the sample who had had very limited experience of USUs (for example, individuals who had enlisted 
and participated for a very limited time before leaving) or a stated and overtly critical view of the units on the basis of either no experience or very limited experience. As noted above, the purposes of the interviews was the generation of understanding from an informed perspective, about how USU participation might be of value in post-graduate life. It was clear from the interviews that our respondents had a range of motivations for participating in the research, including positive experience, critical assessment and curiosity about the viability and future of the units.

Interviews were structured around a schedule (see Appendix 2), which established a core set of questions and answers, and facilitated further probing and exploration of issues as they arose during the interview. They were either conducted face-to-face at a venue of the respondent's choosing, or via telephone or Skype. All interviews were audio recorded. All interviewees were given an outline of the project prior to the interview, and were required to provide signed confirmation of their informed consent to the interview, its recording and subsequent analysis of data. The interviews were transcribed and the transcripts cleaned to ensure accuracy and respondent anonymity. Only one member of the research team had access to information matching each interview transcript to an individual's name and contact details.

Once transcribed, the interviews were coded using NVivo version 10 software (QSR International), enabling all respondent answers to a specific question to be collated together. These were then coded using the constant comparative method by members of the research team-working directly with the coded collated transcripts on specific questions. ${ }^{52}$

\subsubsection{Interviews with representatives from the armed forces}

The purpose of these interviews was to generate data on the value of the USUs from the perspective of those charged with their organisation, management and individual strategic direction. We chose to focus on unit COs (or Officers Commanding in the case of UASs) because we were interested in the detail of practical experience coupled with the wider expertise, experience and insight of officers working with USUs at that level (that is, officers of the rank of Lieutenant Colonel for OTCs, Squadron Leader for UASs and Lieutenant for URNUs). We did not, therefore, pursue either more junior officers or senior non-commissioned officers (NCOs) involved in unit management and training, nor more senior officers working within the three services or MoD with strategic overview but without direct unit responsibility. That said, our insights

${ }^{52}$ Glaser, B. G. and Strauss, A. L. (1967). The Discovery of Grounded Theory: Strategies for Qualitative Research. Aldine De Gruyter, New York; Strauss, A. L. and Corbin, J. (1990). Basics of Qualitative Research: Grounded Theory Procedures and Techniques. Sage Publications: Newbury Park, CA. 
about the value of the units for the armed forces were enhanced through more informal conversations with senior and junior personnel in the course of doing the research, and we are grateful to those individuals for sharing their observations with us.

Given the number of units (46 in total: 18 OTCs/OTRs ${ }^{53}, 14$ UASs and 14 URNUs), we identified five different localities around the UK from which to sample interviewees. We have maintained the anonymity of respondents and units by not naming these localities here. The five localities included a range of different types of university ('ancient', 'red brick', 'plate glass' and 'new') with different student socioeconomic and academic (pre-entry qualification) profiles, from regions around the UK with markedly different regional demographic, economic, social, cultural and geographical characteristics, and different regional traditions of military presence and military recruitment. Within these five localities, we interviewed the commanding officers for the local OTC, UAS and URNU, generating a total of 15 interviews. All unit COs who were approached agreed to be interviewed, and we are very grateful to them all for sharing their time and insights with us.

The same protocols for informed consent, interview schedules, data recording, data coding and data analysis were followed as with the graduate interviews. The interview schedule is reproduced in Appendix 3.

\subsubsection{Interviews with representatives from universities}

The purpose of these interviews was to generate information and understanding about the value of the USUs from the perspective of the universities. Although units may not be located in or near university campuses and facilities, and may not have close contacts with universities beyond MEC representation, the universities have a distinct interest in the question of the value of the units because of student participation. Universities are not responsible for the organisation, administration or strategic direction of the USUs, which is properly the responsibility of the parent services. However, universities have a potential interest in military and defence matters because of the employment destinations of their graduates (which will include the armed forces and the broader defence sector), because of links which may exist through research interests in defence or military issues, and because of cultural and political factors shaping the public reputation or perception of individual universities.

We explicitly did not seek to interview representatives who we knew had experience of USUs through their MEC participation. We focused our interviewee recruitment on senior university administrative officers with responsibility for

\footnotetext{
${ }^{53}$ Note that this is the number of units, and some have one or more additional detachments to account for the geographical extent of their catchment area.
} 
student recruitment, student progression and student experience. Most commonly, these were academic registrars (although not all universities use this title). We were interested in this group because we were interested, in part, in levels of knowledge about and understanding of USUs at this level. We explore further features of our sample in Chapter 6 below. In brief, although having initially intended to match our CO sample with interviews with university representatives associated with those units, having generated a greater number of graduate interviews than originally intended, we confined ourselves to one geographical region which had within it both representation from all three units and universities across the range of the sector.

We contacted registrars from the five institutions represented in that region. One declined to be interviewed on the grounds that the individual concerned felt they knew nothing about the units (despite students from that universities participating in USUs) and preferred not to participate. However, within the sample we also had another university occupying a similar position in the higher education sector, so overall this omission was not felt to be detrimental to the sample. Another interviewee initially declined to be interviewed on similar grounds, but was persuaded that their self-perceived lack of knowledge about the units was in fact of interest to the research team, given that students from that institution participated in USUs and yet there appeared little knowledge of the units at a high level within that institution. The same protocols for interview schedule, informed consent, recording, coding and analysis was followed as described above for the interviews with graduates and with COs. The interview schedule is reproduced in Appendix 4.

\subsubsection{Interviews with employers}

Included in the first objective for this research (see 2.1.2 above) was an intention to interview a sample of employers. The interviews were to be conducted by telephone, using a short interview schedule. The sample was to be derived from The Times Top 100 Graduate Employers. However, this element of the research did not proceed as planned. It proved virtually impossible to make contact directly with senior company representatives with responsibility for recruitment, not least because of the absence of available contact information, particularly for large (often international) companies. In addition, it transpired that a number of recruiters screened initial graduate applications via recruitment agencies. Although the possibility was raised of using contacts via the Support for Britain's Reservists and Employers organisation (SaBRE), this would have resulted in a skewed sample, potentially generating interview contacts who were known to already have knowledge and understanding of the transferability (or otherwise) of skills derived in military contexts to civilian employment contexts.

However, the other data collection strategies we used with students, graduates, and, to an extent, COs and university representatives, did generate sufficient 
data to enable us to explore some of the issues around perceptions by graduate recruiters of the value (or otherwise) of the USU experience in terms of the inculcation of graduate skills. The student survey asked students about their experiences of engagement with the recruitment process, and generated quantitative and qualitative data on this. The interviews with graduates included a substantial focus on the experience of applying for and being recruited to organisations, and of being a recruiter, and thus generated qualitative data on the use of the USU experience by individuals seeking employment. Given the time constraints of the project, a decision was made to focus our efforts on the analysis of this data, rather than continuing with the seemingly fruitless task of trying to contact recruiters directly.

\subsection{Conclusions on rationale and methodology}

Despite the issues encountered in exploring directly the opinions of recruiters and employers of the value of USUs, the research project proceeded as intended, and the remainder of this book sets out the empirical results in full.

Prior to, and during the course of the research, a number of questions were raised by the research team and others concerning issues that the research did not explore; we include them here both for clarification and because they might indicate areas for future research on the broad topic of USUs and their value.

The first concerns the potential for a longitudinal element to the student survey. The survey provided a snapshot of a set of experiences and explanations from the surveyed cohort at a particular point in time. There was no intention at the time to repeat the survey and thereby develop a longitudinal data set able to capture continuity and change over time. That said, we include the original survey instrument in Appendix 1 should a repeat survey be thought feasible and useful at a future point in time.

The second concerns the capture of information from those with USU experience who went on to pursue careers in the Regular armed forces. Because the intention of the research was to focus on the value of the USU experience for those who did not join the Regulars, we made no attempt to capture data from this group. That said, it became clear during conversations (particularly with unit COs) both that there may be utility for the armed forces in being able to track whether a USU experience proves beneficial to those who pursue military careers, and that there is an absence of knowledge, beyond the anecdotal, within the armed forces of a more basic set of indicators about the presence or absence of a USU background amongst those pursuing military careers. Of particular interest were questions about the utility to individuals of the USU experience in providing military and transferable skills which then proved beneficial to the armed forces recruitment and training process and thence in career development, and questions about the utility to the armed forces in terms of the existence (or otherwise) of a cohort of individuals pursuing careers as officers 
who had previously had a USU experience. We note here that research to collect reliable data on USU experience and military career progression would be relatively straightforward to undertake.

The third concerns the comparability between the USU experience and that derived from other non-academic student activities. As this book will show, a significant element of this research examined the skills and wider experiences generated by one specific type of university activity. Although our student survey asked USU participants to evaluate their skills development in USUs in comparison with those from other activities, we did not set out to examine a control group who did not have USU experience to deliberately compare USU and non-USU value. This was partly because of time and resourcing (the research was deliberately focused on active USU participants), and also because of the difficulty of finding, amongst the plethora of student non-academic activities, a suitable sample of control activities against which the USU experience could be compared. Again, with sufficient care and attention to the methodological difficulties in establishing a control group, this is potentially an issue where future research could be undertaken.

The fourth concerns the experience of students who may have had a brief USU experience (that is, may have joined a unit following selection, but subsequently withdrew after a period of a few months). We can hypothesise that there would be a set of reasons for withdrawal, including negative views of the USU and its mission, health and medical reasons, and competing academic and other commitments. We made no attempt to engage with this disparate group, either amongst current students or amongst graduates, because we were interested in active participants and thus the value that they as students and graduates felt that they were getting or had gained through their participation. It is possible that this may be an area for further research, although the insights gained from such an exercise would most likely generate little further than confirmation of the hypotheses outlined above.

The final point to make about the research rationale and methodology is that although they are presented here as quite discrete exercises in data generation targeting four quite different groups, in fact the student questionnaire and the interview schedules were deliberately designed to explore similar themes from the perspectives of the different groups (students, graduates, COs and university representatives). There is thus, in the overall dataset, considerable potential for comparative analysis of particular themes such as value, skills development, workplace performance, employability and university benefit. In the following four chapters, we focus in turn on the data and results of data analysis for each group, and bring together key findings from all four groups in the concluding chapter. 